\title{
Retrograde endosonography-guided hepaticojejunostomy after failed rendezvous in a patient with Child's resection
}
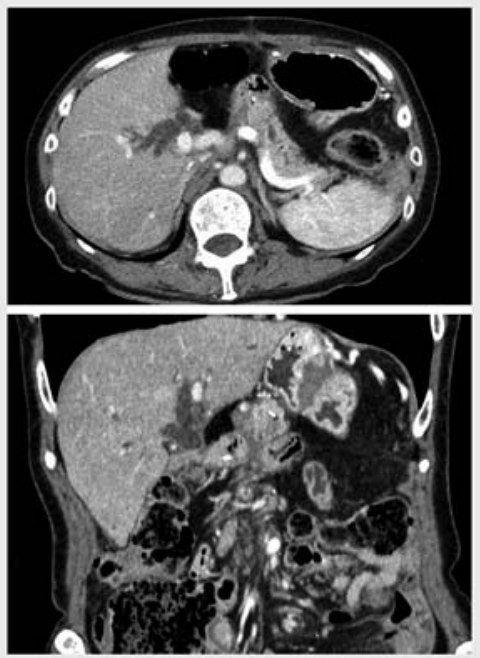

- Fig. 1 Contrast computed tomography (axial and coronal views) revealed biliary obstruction at the choledochojejunal anastomosis with no visible tumor.

Percutaneous or endoscopic ultrasoundguided hepaticojejunostomy (EUS-HJS) is infrequently used for antegrade stent placement or dilation for subsequent endoscopic retrograde cholangiography (ERC) in stenotic bile ducts of patients with surgically altered anatomies [1-3]. However, an alternative approach is required in severe strictures precluding guidewire passage.

A 65-year-old woman who underwent subtotal stomach-preserving pancreaticoduodenectomy with Child's resection for Stage II pancreatic cancer 3 months prior presented with fever, jaundice, and tachycardia. Contrast computed tomography $(C T)$ revealed biliary obstruction at the choledochojejunal anastomosis with no visible tumor ( $>$ Fig. 1 ). No bile was observed in the afferent limb and the choledochojejunal anastomosis could not be cannulated. Percutaneous transhepatic biliary drainage (PTBD) was performed and symptomatic improvement was observed.

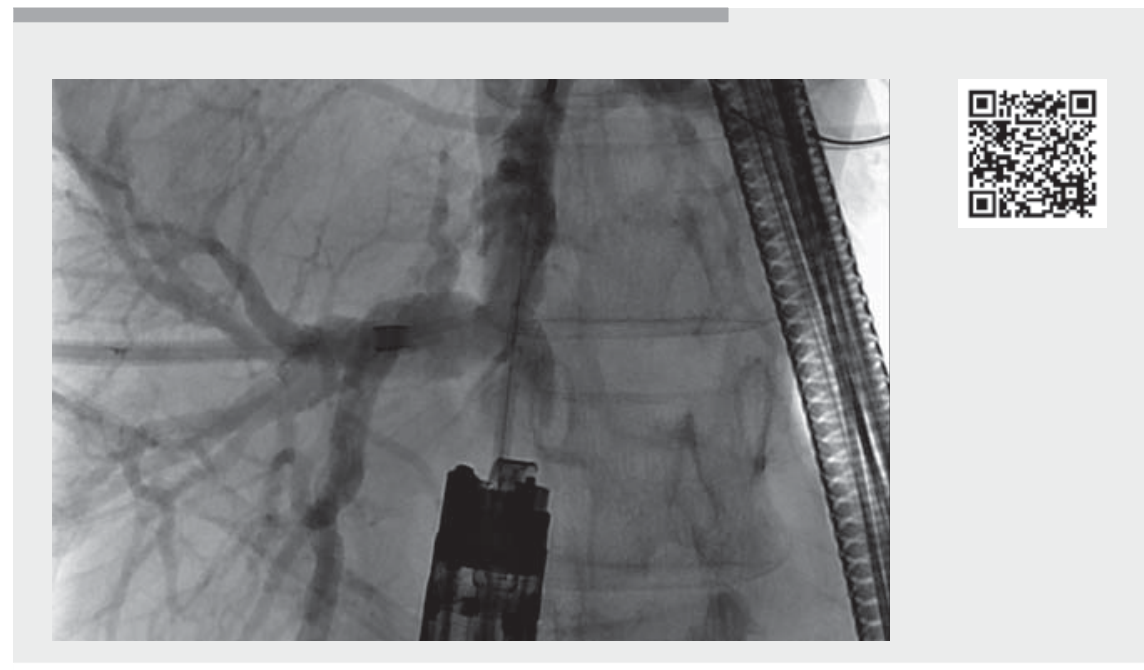

$\nabla$ Video 1 Retrograde endosonography-guided hepaticojejunostomy was performed after a guidewire inserted through the percutaneous biliary drainage catheter failed to pass through the stenotic choledochojejunal anastomosis.

While ERC using the rendezvous technique was attempted 10 days later, a guidewire inserted from the PTBD route could not pass through the stenotic anastomosis. A forward-viewing endosonoscope (TGF-UC260]; Olympus Corp., Tokyo, Japan) was therefore advanced near the anastomosis to identify the bile duct under EUS guidance. The enteric wall was punctured under EUS guidance using a 19-gauge EUS needle (EZShot3; Olympus) where the bile duct was viewed closest to the scope ( $\mathbf{F i g . 2} \mathbf{a}, \mathbf{b}$ ). A guidewire was advanced into the intrahepatic bile duct and confirmed on fluoroscopy ( Fig.2c). A plastic stent was placed after mechanical dilation ( $\mathbf{F i g . 2 d}$ ). Contrast injected from the PTBD catheter flowed smoothly into the afferent limb, confirming successful drainage ( $\mathbf{F i g} \mathbf{2}$ e, - Video 1). No complications were observed on follow-up CT and the patient was discharged 4 days later ( $>$ Fig.3). The patient remained symptom-free at 24 months with periodic stent replacement.
While there are reports of conversion to EUS-guided hepaticogastrostomy for PTBD catheter internalization after ERC failure $[4,5]$, retrograde EUS-HJS may be another alternative in severe benign anastomotic stenosis when the anastomosis can be reached with a forward-viewing endosonoscope.

Endoscopy_UCTN_Code_TTT_1AS_2AD

\section{Competing interests}

The authors declare that they have no conflict of interest. 

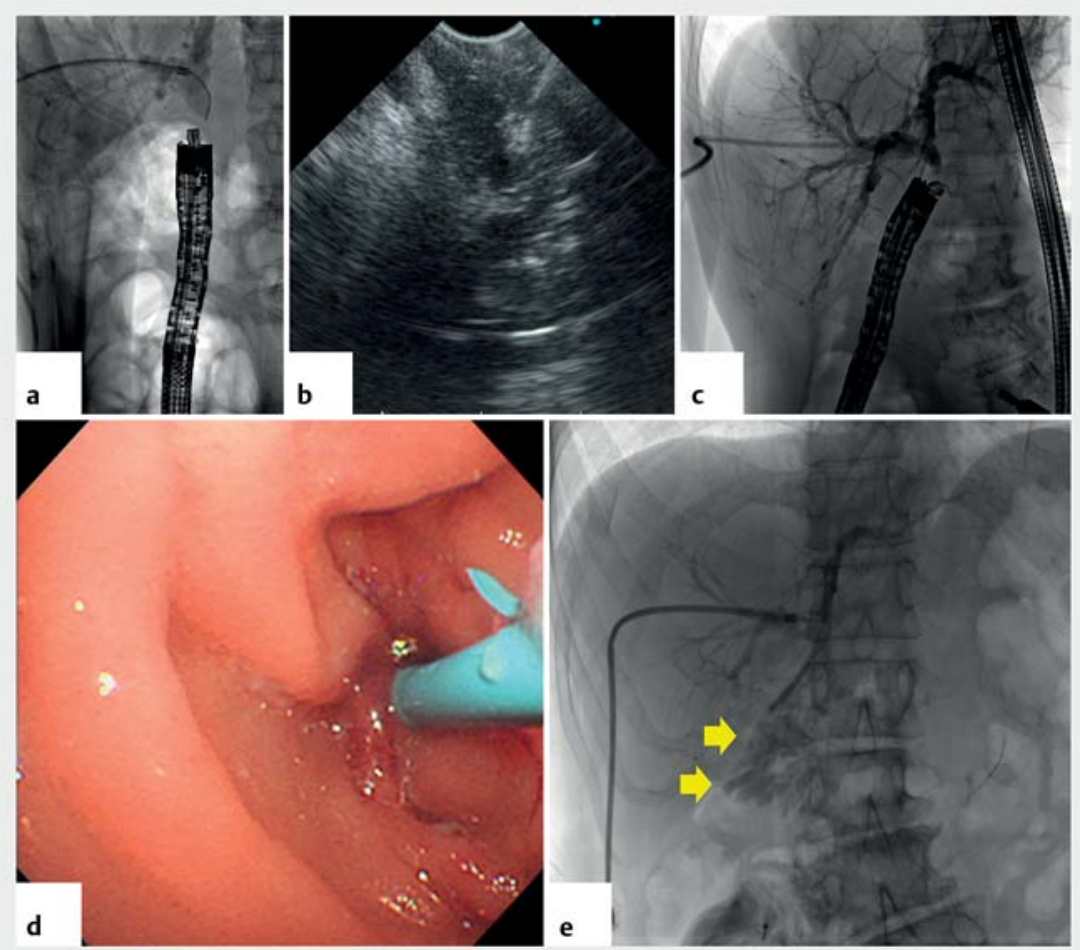

- Fig. 2 Retrograde endosonography-guided hepaticojejunostomy. a The forward-viewing endosonoscope was advanced near the choledochojejunal anastomosis to the optimal puncture site under fluoroscopic and endosonographic guidance. $\mathbf{b}$ The bile duct was punctured with a 19-gauge needle. c Fluoroscopy confirmed proper wire placement. d A plastic stent was placed through the hepaticojejunostomy after mechanical dilation. e Contrast injected from the percutaneous transhepatic biliary drainage catheter flowed smoothly into the afferent limb (yellow arrows), confirming successful drainage.

\section{The authors}

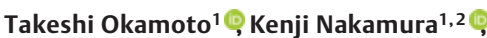
Minoru Yabuta ${ }^{3}$, Katsuyuki Fukuda ${ }^{1}$

1 Department of Gastroenterology, St. Luke's International Hospital, Tokyo, Japan

2 Department of Gastroenterology, Tokyo Dental College, Ichikawa General Hospital, Chiba, Japan

3 Department of Radiology, St. Luke's International Hospital, Tokyo, Japan

\section{Corresponding author}

\section{Kenji Nakamura, MD, PhD}

Department of Gastroenterology, Tokyo Dental College, Ichikawa General Hospital, 5-11-13, Sugano, Ichikawa,

Chiba 272-8513, Japan

kenakamura@tdc.ac.jp

\section{References}

[1] Maehara K, Hijioka S, Nagashio Y et al. Endoscopic ultrasound-guided hepaticogastrostomy or hepaticojejunostomy without dilation using a stent with a thinner delivery system. Endosc Int Open 2020; 8: E1034E1038

[2] Ueshima K, Ogura T, Nishioka N et al. Technical feasibility of EUS-guided antegrade dilation for hepaticojejunostomy anastomotic stricture using novel endoscopic device (with videos). United European Gastroenterol J 2019; 7: 419-423

[3] James TW, Fan YC, Baron TH. EUS-guided hepaticoenterostomy as a portal to allow definitive antegrade treatment of benign biliary diseases in patients with surgically altered anatomy. Gastrointest Endosc 2018; 88: 547-554

[4] Paik WH, Lee NK, Nakai Y et al. Conversion of external percutaneous transhepatic biliary drainage to endoscopic ultrasound-guided hepaticogastrostomy after failed standard internal stenting for malignant biliary obstruction. Endoscopy 2017; 49: 544-548

[5] Law R, Sanchez-Ocana Hernandez R, de la Serna-Higuera $C$ et al. EUS-guided biliary

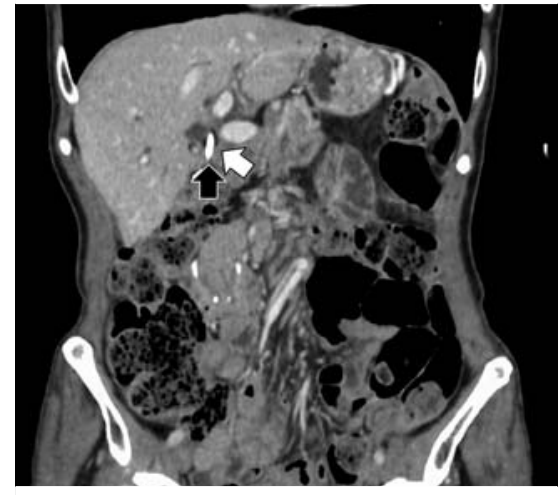

- Fig. 3 Follow-up contrast computed tomography (coronal view) showed the plastic stent inserted through the hepaticojejunostomy (black arrow), which was located near the stenotic choledochojejunal anastomosis (white arrow). No complications were observed.

drainage for internalization of percutaneous transhepatic biliary drainage. VideoGIE 2017; 2: 301-302

Bibliography

Endoscopy 2022; 54: E131-E132

DOI $10.1055 / a-1443-4244$

ISSN 0013-726X

published online 20.4.2021

(c) 2021. Thieme. All rights reserved. Georg Thieme Verlag KG, Rüdigerstraße 14, 70469 Stuttgart, Germany

\section{CORRECTION}

Retrograde endosonography-guided hepaticojejunostomy after failed rendezvous in a patient with Child's resection

Okamoto T, Nakamura K, Yabuta M et al. Retrograde endosonography-guided hepaticojejunostomy after failed rendezvous in a patient with Child's resection.

Endoscopy 2021, 53: doi:10.1055/a1443-4244

In the above-mentioned article, the title has been corrected. Correct is: Retrograde endosonography-guided hepaticojejunostomy after failed rendezvous in a patient with Child's resection. There have also been made corrections in the text. Correct is that the patient underwent Child's resection for pancreatic cancer. This was corrected in the online version on November 24, 2021. 